EPJ Web of Conferences 82, 01006 (2015)

DOI: $10.1051 /$ epjconf/20158201006

(C) Owned by the authors, published by EDP Sciences, 2015

\title{
Temperature patterns in the gas infrared radiator heating area
}

\author{
N.I. Kurilenko², G.Ya. Mamontov ${ }^{1, a}$ and L.Yu Mikhaylova² \\ ${ }^{1}$ National Research Tomsk Polytechnic University, 634050 Tomsk, Russia \\ ${ }^{2}$ Tyumen State University of Architecture and Civil Engineering, 625001 Tyumen, Russia
}

\begin{abstract}
The obtained results of experimental studies provide the basis for the heat transfer mechanism specification on the studied conditions that are typical for many practical applications. It was proved appropriateness of the natural convection and heat conduction process simulation while analyzing the heat transfer in rectangular enclosures with the radiant heating sources at the high bound.
\end{abstract}

\section{Introduction}

The heat transfer processes with the local lumped heating sources in enclosures are intensively studied in theoretical terms over recent years (e.g. [1-4]). A few articles (typical articles [5, 6]) are published on essential heat transfer characteristics experimental data in conditions that are typical for many practical applications. Moreover, the experiments of $[5,6]$ type were carried out with the typical size models that are much smaller than the corresponding size significant facilities (e.g. heat supply facilities). It is necessary to perform the theoretical results analysis feasibility of these processes involving the experiment results obtained with the models that have the maximum approximate size to the real models.

It is possible to use the diverse alternates of the heating sources layout on the model internal surfaces [1-6]. The heat transfer process in the rectangular enclosure with the radiant heating source that is at the area high bound (or next to it), is the least understood. The gas infrared radiator (GIR), for instance, can be used for this source [7].

The work objective is to study the temperature patterns in the air-filled large-sized space with heaters on its top surface.

\section{Results and discussion}

The field research was carried out with the large-sized models of the large typical size (from $11 \mathrm{~m}$ to $24 \mathrm{~m}$ ) in winter at an outer air temperature from $-5^{\circ} \mathrm{N}$ to $-42^{\circ} \mathrm{N}$. They studied the temperature patterns formed when GIR that are at the upper part of the temperature logging area (fig. 1) operate. The internal air relative humidity was $<65 \%$.

\footnotetext{
${ }^{a}$ Corresponding author: marisha@tpu.ru
}

This is an Open Access article distributed under the terms of the Creative Commons Attribution License 4.0, which permits unrestricted use, distribution, and reproduction in any medium, provided the original work is properly cited. 


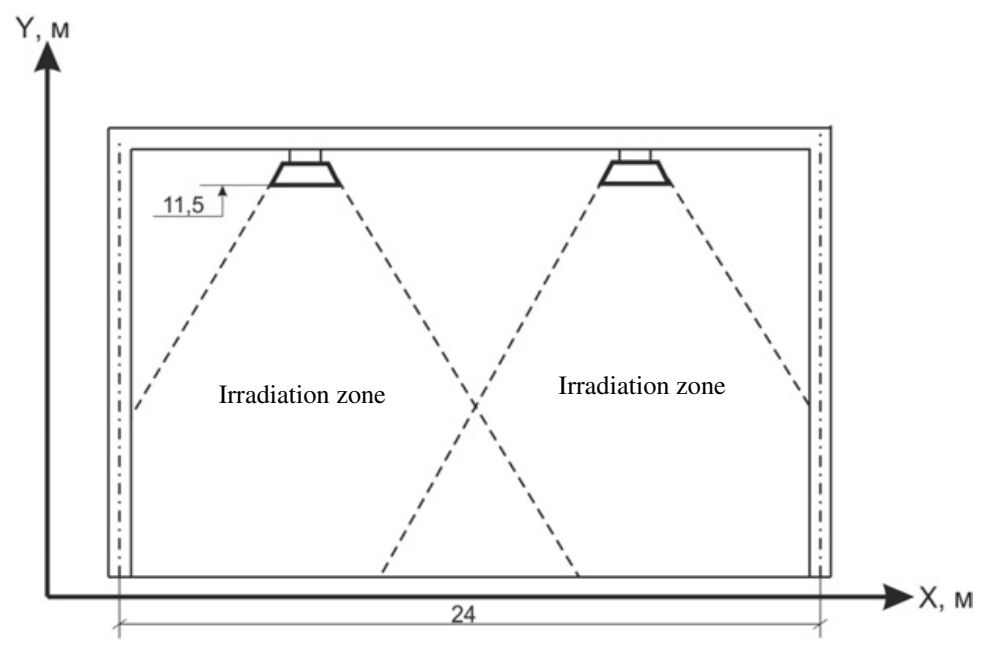

Figure 1. Field research operations area scheme.

The heating system included ten K $8430 \mathrm{RN}$ heaters produced by "GoGas" company (Germany) having a heating capacity for $30 \mathrm{~kW}$ each. The average density of the radiant heat flux was $\sim 25 \mathrm{~W} / \mathrm{m}^{2}$ at the lower bound of the area (Fig. 1), at the height of $\sim 1,7 \mathrm{~m}-100 \mathrm{~W} / \mathrm{m}^{2}$.

The heaters ran flat to the lower bound at the height of $11,5 \mathrm{~m}$. The measurements were taken by thermal converters in cross sections between the heaters (at regular intervals from them). On the results of measurements, the heating patterns along the Y-axis were determined. The typical heating pattern is presented in Fig. 2.

The primary statistical analysis of experiment results showed that the sample mean is equal to $t=19,05^{\circ} \mathrm{C}$ at unbiased estimate of the mean square deviation $S=2,01$. It is possible to draw a conclusion that $95 \%$ of temperature experimental values is in the range of $(15,03 ; 23,07)$.

The correlation index of smoothed measurement results is equal to 0,65 . It proves the interconnection $t(y)$, and the relation in Fig. 2 illustrates this connection nonlinearity.

The regression equation is set up. The graphic representation specification showed that the non-linear regression fourth degree mode appears to be the best:

$$
t=0,00 y^{4}-1,162 y^{3}+1,611 y^{2}-4,929 y+21,325 .
$$

To calculate the estimated regression coefficient, at the first stage the equation linearization through substitution was carried out: $Z_{1}=y ; Z_{2}=Y^{2}, Z_{3}=y^{3} ; Z_{4}=y^{4}$. On the result, the multiple regression linear model was obtained:

$$
t=b_{0}+b_{1} \mathrm{z}_{1}+b_{2} \mathrm{z}_{2}+b_{3} \mathrm{z}_{3}+b_{4} \mathrm{z}_{4}+\varepsilon .
$$

The $b_{0}, b_{1}, b_{2}, b_{3}, b_{4}$ estimated coefficients were obtained by the ordinary least squares technique for multiple regressions.

The estimated coefficient standard errors were determined in proving the coefficient statistical significance of the obtained regression equation. The Student distribution critical value is set according to the critical point appropriate tables at significance level 5\%. It is concluded that all coefficients of the obtained regression equation are statistically significant.

The determination coefficient $R^{2}=0,989$ demonstrates the symbolic model high performance that is obtained through experiments. Its statistical significance is also determined at $5 \%$ level via use of Fisher distribution statistics. 


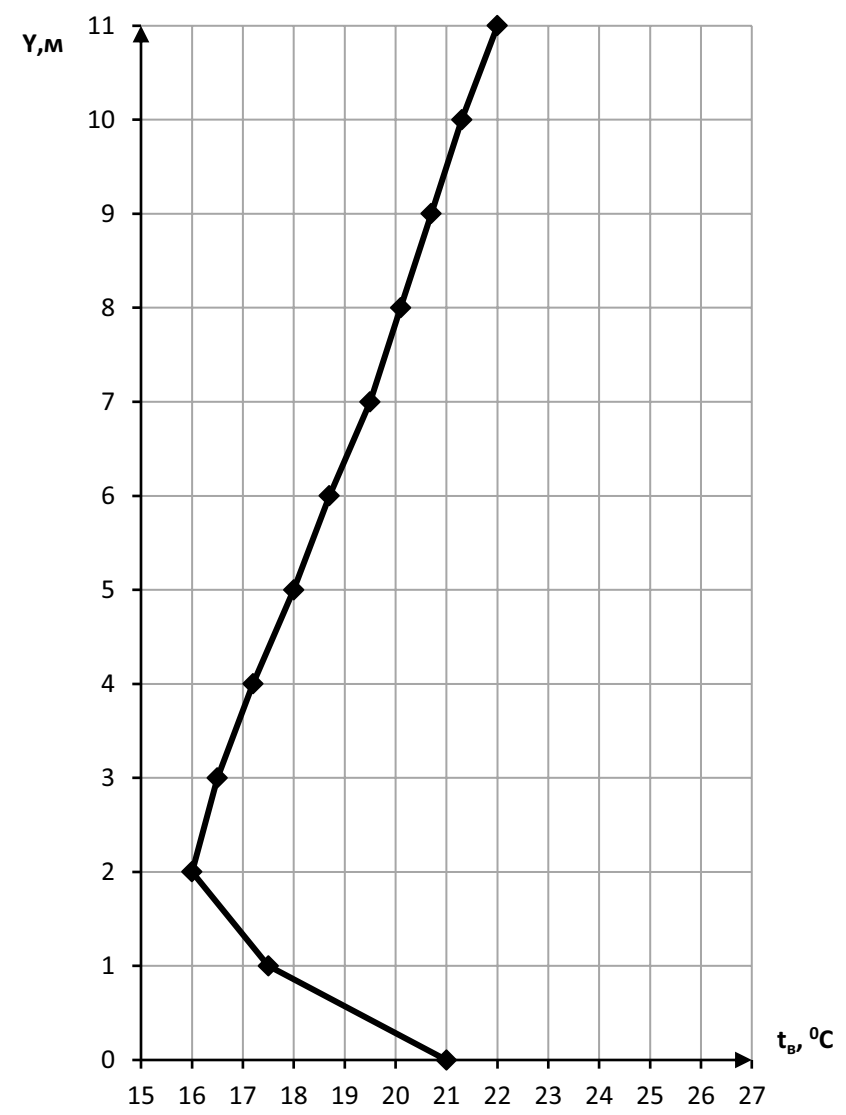

Figure 2. Heating patterns along the $\mathrm{Y}$-axis in cross section $\mathrm{x}=12,0$ between two heaters.

The table of temperature empirical values and values calculated through the regression formula is given below (1). The total of the result uncertainties is moderately different from null. Therefore, it is settled that one of the Gauss-Markov conditions that fix prerequisites for the ordinary least squares technique use is met.

The fulfillment of the second Gauss-Markov condition on the constant deviation variance $\varepsilon_{i}$ for any experimental observations $i$ and $j: D\left(\varepsilon_{i}\right)=D\left(\varepsilon_{j}\right)=\sigma^{2}$ was proved with the aid of the Spearmen's rank-order correlation test.

It is shown because of the statistical analysis that conclusions made above following F-statistics are reliable.

The obtained results of experimental studies provide the basis for the heat transfer mechanism specification on the studied conditions that are typical for many practical applications.

The temperature distribution with respect to the coordinate $y$ (Fig. 2) in a typical cross section in $x$ illustrates the features of the studied process. The heat that is generated by the gas infrared radiators enters into the area lower bound and is accumulated by the thin boundary layer of the horizontal wall. This wall surface temperature grows and creates conditions to heat the air lower layers that bear against the bound $y=0$. As a result, the free-convection streams are formed and they carry out the lower wall cooling and air upper layers heating. The temperature local minimum at the level of $y \approx 2 m$ is responsible for the cooperative effect of natural convection processes and air conduction. By virtue of research results, it is possible to draw a conclusion on appropriateness of the natural convection and 
Table 1. The experimental $\left(t_{3}\right)$ and calculated by regression formula $\left(t_{p}\right)$ temperature values.

\begin{tabular}{|c|c|c|c|}
\hline $\mathrm{y}, \mathrm{m}$ & $\mathrm{t}_{3}{ }^{\circ} \mathrm{C}$ & $\mathrm{t}_{\mathrm{p}}$ & $\varepsilon_{i}=\mathrm{t}_{3}-\mathrm{t}_{\mathrm{p}}$ \\
\hline 0,1 & 21,0 & 20,84699 & 0,153011 \\
\hline 1 & 2 & 3 & 4 \\
\hline 1,0 & 17,58 & 17,75078 & $-0,17078$ \\
\hline 2,0 & 16,02 & 16,30932 & $-0,28932$ \\
\hline 3,0 & 16,42 & 16,24349 & 0,176508 \\
\hline 4,0 & 17,25 & 16,94095 & 0,309045 \\
\hline 5,0 & 18,07 & 17,93416 & 0,135842 \\
\hline 6,0 & 18,7 & 18,90032 & $-0,20032$ \\
\hline 7,0 & 19,4 & 19,66143 & $-0,26143$ \\
\hline 8,0 & 20,12 & 20,18425 & $-0,06425$ \\
\hline 9,0 & 20,72 & 20,5803 & 0,1397 \\
\hline 10,0 & 21,32 & 21,1059 & 0,214102 \\
\hline 11,0 & 22,02 & 22,16211 & $-0,14211$ \\
\hline
\end{tabular}

heat conduction process simulation while analyzing the heat transfer in rectangular enclosures with the radiant heating sources at the high bound.

\section{Conclusions}

By virtue of the results of the temperature patterns undertaken experimental studies in rectangular enclosure with the radiant heating source (gas infrared radiators) next to the high bound, it is possible to draw a conclusion on the heat transfer mechanism in the studied conditions that are quite typical for many practical applications. The air heat transfer that fills the space of interest is carried out through the combined processes of natural convection and heat transfer.

\section{References}

[1] Kuznetsov, G.V., Sheremet, M.A. Two-dimensional problem of natural convection in a rectangular domain with local heating and heat-conducting boundaries of finite thickness// Fluid Dynamics, 41, Issue 6, November 2006, Pages 881-890

[2] Kuznetsov, G.V., Sheremet, M.A. New approach to the mathematical modeling of thermal regimes for electronic equipment// Russian Microelectronics, 37, Issue 2, March 2008, Pages 131-138

[3] Kuznetsov, G.V., Sheremet, M.A. Mathematical modelling of complex heat transfer in a rectangular enclosure// Thermophysics and Aeromechanics, 16, Issue 1, March 2009, Pages 119-128

[4] Kuznetsov, G.V., Sheremet, M.A. Conjugate natural convection in an enclosure with local heat sources// Computational Thermal Sciences, 1, Issue 3, 2009, Pages 341-360

[5] Kuznetsov, G.V., Maksimov, V.I., Sheremet, M.A. Natural convection in a closed parallelepiped with a local energy source// Journal of Applied Mechanics and Technical Physics, 54, Issue 4, July 2013, Pages 588-595

[6] Samo Venko, Daniel Vidal de Ventós, Ciril Arkar, Sašo Medved. An experimental study of natural and mixed convection over cooled vertical room wall// Energy and Buildings, 68, Part A, January 2014, Pages 387-395

[7] Kuznetsov, G.V., Kurilenko, N.I., Maksimov, V.I., Mamontov, G.Ya., Nagornova, T.A. Heat transfer under heating of a local region of a large production area by gas infrared radiators// Journal of Engineering Physics and Thermophysics, 2013, Pages 1-6 